\title{
Development of palmarosa oil microcapsules
}

\author{
POONAM KUMARI, NEELAM M. ROSE AND SAROJ S. JEET SINGH
}

Received: 27.02.2017; Revised: 11.04.2017; Accepted: 28.04.2017

See end of the paper for authors' affiliations

\section{POONAM KUMARI}

Department of Textile and Apparel

Designing, I.C. College of Home Science,

C.C.S. Haryana Agricultural University,

HISAR (HARYANA) INDIA

Email : minkusmile@gmail.com
ABSTRACT : Natural fragrant microcapsule with gelatin and gum as a wall material palmarosa as a core material were prepared by complex cocervation technique. Different variables, including ratio of essential oil, gum, gelatin, temperature and $\mathrm{pH}$ were optimized on the basis of comparative analysis through visual assessment under inverted microscope. Result showed that medium sized microcapsules having sharp and thick wall and good uniformity in size and distribution were formed at ratio of 1:2:4 of oil, gum and gelatin, at a temperature of $50^{\circ} \mathrm{C}$ with initial and final pH 4.5 and 9.0, respectively. Hence, these optimized ratios were selected for preparation of microcapsules.

KEY WORDS: Cocervation technique, Gelatin, Microcapsule, Palmarosa oil

- HOW TO CITE THIS PAPER : Kumari, Poonam, Rose, Neelam M. and Singh, Saroj S. Jeet (2017). Development of palmarosa oil microcapsules. Asian J. Home Sci., 12 (1) : 149-154, DOI: 10.15740/HAS/ AJHS/12.1/149-154. 